\title{
Comunicación y poder: dos elementos inseparables
}

Carmina C. Ortega Moreno ${ }^{1}$

Benemérita Universidad Autónoma de Puebla, México

\section{Reseña de libro}

Mendieta, A; \& Estrada, J. L. (2018). Comunicación política, instituciones y gobernabilidad en México. México: Benemérita Universidad Autónoma de Puebla; Madrid: Comunicación Social Ediciones y Publicaciones. 162 pp. ISBN: 978-84-17600-00-6

Material original autorizado para su primera publicación en el Journal de Ciencias Sociales, Revista Académica de la Facultad de Ciencias Sociales de la Universidad de Palermo

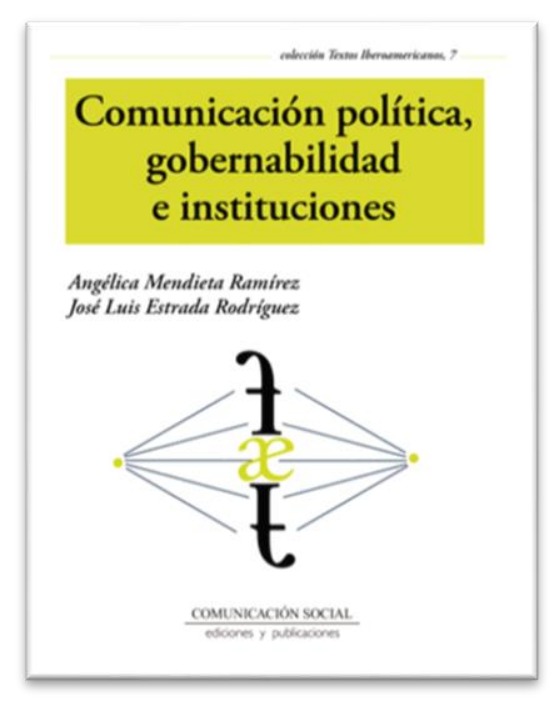

Resumen: El libro Comunicación política, instituciones y gobernabilidad en México de Angélica Mendieta Ramírez y José Luis Estrada Rodríguez presenta una serie de argumentos en torno la emisión de mensajes políticos, las estrategias de comunicación masiva, el desempeño del rol de los organismos del Estado y la forma de gobierno del país, mencionando acciones realizadas tanto por el gobierno de Estados Unidos como por el gobierno de México en relación con la información y la comunicación política. Su obra presenta una serie de ideas argumentadas en torno a la política y la gobernabilidad, motivo por el cual esta producción se considera una herramienta esencial para el investigador en el área de comunicación política.

\footnotetext{
${ }^{1}$ Maestra en Educación Superior y Licenciada en Filosofía por parte de la Benemérita Universidad Autónoma de Puebla (BUAP). Correo electrónico: carmi_car@hotmail.com
} 


\section{Introducción}

El libro Comunicación política, instituciones y gobernabilidad en México tiene la finalidad de dar a conocer de qué manera se constituye la comunicación política en México además de mostrar una reflexión en torno a los cambios en el contexto histórico de la comunicación política. Retoma a autores como Maarek (2008), al asegurar que la comunicación política se encuentra "en la encrucijada de tres disciplinas: las ciencias de la comunicación, la ciencia política y la mercadotecnia." (p.92), y hace alusión a la multidisciplinariedad de la comunicación política. Entre otros aspectos, el texto plantea una serie de ideas acerca de la relación de quienes gobiernan y sobre quienes se ejerce esta autoridad de manera legítima. De esta manera, brinda al lector una herramienta orientada a promover el cambio en la sociedad.

\section{Comentarios}

El libro describe cómo se construyen los mensajes políticos, las estrategias de comunicación masiva y el vínculo entre las instituciones política del Estado. Elabora una explicación para entender cómo el discurso de los gobernantes produce legitimación en sus acciones a partir de las políticas públicas.

En la introducción, los autores expresan la multidisciplinariedad de la comunicación política, al mismo tiempo que adelantan algunas de las ideas que desarrollan en su texto a fin de motivar al lector a profundizar en los contenidos que abordan a lo largo de la obra. Ya lo mencionan Reyes, O’ Quínn, Morales y Rodríguez: "es importante destacar que la comunicación en su perspectiva política tiende a buscar un mejor entendimiento entre los integrantes que componen la sociedad y entre ésta y el grupo gobernante" (2011, p.87).

En la sección I, Comunicación y mercadotecnia política, se explica de qué manera la comunicación forma parte del desarrollo social en tanto proceso de múltiples direcciones en las cuales se presenta un intercambio de información entre distintos grupos. Además, en esta sección se define el concepto de gobernanza y se da a conocer una perspectiva de las corrientes de la comunicación política. A su vez, se describe -a partir de mediados del siglo pasado- cómo se utilizó la mercadotecnia para presentar a los candidatos ante los electores, ello como una estrategia política para la obtención de votos. Entre otros aspectos, cabe destacar la importancia que juegan las redes sociales en los medios de comunicación sobre la imagen y la concepción de los candidatos. También se mencionan las metodologías a partir de la cuales se desarrolla el estudio de la comunicación política a partir del uso de elementos que forman parte de la mercadotecnia. 
En la sección II, Comunicación Digital y Gobierno Abierto, los autores explican la forma en que la comunicación, como un acto social, se desarrolla en un contexto determinado en el cual estar informados no siempre implica comprender o conocer en profundidad el quid de algún asunto o situación específica, motivo por el cual los investigadores deben recopilar información de diversas fuentes para evitar la desinformación o la sub-información, dos conceptos, estos últimos, a los que se dedican algunas líneas concretas en esta parte del libro. Asimismo, se menciona la importancia de las tecnologías en el desarrollo de las actividades sociales y políticas. Entre otros aspectos, se hace referencia a la Teoría del Espiral del Silencio con la cual se explica cómo las personas tienen interés en pertenecer a un círculo social en el cual las opiniones emitidas permiten la integración y aceptación de sus pares, semejante a lo que ocurre en determinados grupos de personas que simpatizan con algún candidato político.

Sumado a esto, el libro se refiere a los medios de comunicación como promotores de actos perlocutivos al momento de realizarse la votación, lo que permite a los electores seleccionar al candidato que aquellos consideran que representa de mejor manera sus intereses. Así pues, en esta sección se reconocen las modalidades de la comunicación que se desarrollan en contextos sociales determinados, en los que la difusión de la imagen política trasciende los medios tradicionales para alcanzar las redes sociales. Un párrafo especial merece el concepto "mass self-communication" (Castells, 2007) que implica la participación de los usuarios con los productos digitales que construyen una cultura sobre diversos objetos de estudio entre los cuales se destaca lo político.

Sumados a estas ideas sobre la participación en la política, se encuentran los conceptos que abordan los mecanismos de transformación social que influyen en la participación de los sujetos en los procesos tanto culturales como políticos, especialmente en lo que concierne al desarrollo, difusión y uso de programas de desarrollo.

En la sección III, Gobernabilidad y Ciudadanía, los autores distinguen la comunicación política de la comunicación gubernamental, así como su relación con la opinión pública y el manejo de conflictos, sumado a la solución de problemas y el conocimiento respecto a los actos políticos. Por otro lado, llevan a cabo una descripción pormenorizada de las estrategias de comunicación política que influyen en la opinión pública. La cual, por cierto, podría ubicarse en la concepción de las opiniones informales que distingue Habermas al decir: "las opiniones informales se diferencian según el grado de su obligatoriedad (...) [y] son resultados del proceso de culturación normalmente sustraído a la reflexión de cada sujeto" (1986, p. 269). Asimismo, se plantea el rumbo en el cual deben encaminarse las acciones comunicativas en relación con utilidades y resultados, especialmente en la obtención de 
repuestas ante las situaciones sociales, debido a que los grupos de opinión influyen a través de redes sociales en las elecciones de los candidatos.

En esta sección de la obra se expone el concepto sobre la representación política, el tipo de mandato que tienen los representantes y cómo obedecen a distintos intereses. Los autores se inclinan hacia volver al mandato libre como mecanismo de control político. Esta posición es relevante porque se asocia a la construcción de la ciudadanía como sistema en el cual se ejerce la democracia ciudadana en la elección de sus gobernantes. De esta manera los políticos, medios y audiencias conforman una realidad común, en la que cada sector desempeña un rol de participación específico por el cual se desarrollan mecanismo de control y de interacción.

Finalmente, en la sección IV, Apuntes finales, Mendieta y Estrada concluyen acerca de cómo los ciudadanos han arribado al poder por medio de las redes sociales. En este sentido, vale tan solo recordar cómo se han democratizado los medios masivos debido a que cada grupo social conforma diferentes sectores que ejercen determinada autoridad bajo ciertos fines; en los que debería destacar no solo la intención de una trasformación social, sino la práctica libre de la democracia a partir de la gobernanza.

\section{Conclusiones}

A lo largo de los años han surgido diversas áreas de conocimiento, cada una con sus propios intereses de estudio y características, y con el paso del tiempo muchas de ellas se han entremezclado. Ese es el caso de las ciencias de la comunicación y las ciencias políticas, que de su unión se desprende el estudio de la comunicación política como un área de oportunidad para aprender de las estrategias de intercambio de información entre el gobierno y la sociedad. El libro Comunicación política, instituciones y gobernabilidad en México, de Angélica Mendieta Ramírez y José Luis Estrada Rodríguez, resulta de especial interés, no solo para conocer el alcance de la comunicación política en la actualidad, sino también por su novedad en el uso de los conceptos y categorías, brindando una herramienta para acercarnos al conocimiento de esta área en México.

\section{Referencias bibliográficas}

Castells, M. (2007). Communication, power and counter-power in the network society. International Journal of Communication, 1, 238- 266.

Habermas, J. (1986). Historia y crítica de la opinión pública. 3aㅡ edición. México: Editorial Gustavo Gili. 
Maarek, P. J. (2008). La comunicación política, una perspectiva internacional. Telos, cuadernos de comunicación e innovación, (74), 92-97. Recuperado de: https://telos.fundaciontelefonica.com/archivo/numero074/la-comunicacion-politicauna-perspectiva-internacional/

Reyes Montes, M.; O’Quínn Parrales, J.; Morales y Gómesz, J. y Rodriguez Manzanares, E. (2011). Reflexiones sobre la comunicación política. Espacios públicos, 14(30), 85101. 